\title{
Comparative genetic resistance to Ascaridia galli infections of 4 different commercial layer-lines
}

\author{
T. SCHOU, A. PERMIN, A. ROEPSTORFF, P. SØRENSEN ${ }^{1}$ AND J. KJÆR ${ }^{1}$
}

\author{
Section for Parasitology, Department of Veterinary Microbiology, The Royal Veterinary and Agricultural \\ University, Frederiksberg and ${ }^{1}$ Department for Animal Genetics, Danish Institute for Agricultural Science, \\ Tjele, Denmark
}

\begin{abstract}
The objective of the study was to compare the establishment and effect of Ascaridia galli infections in 4 different layer-lines.

2. A total of 160 birds comprising 4 different commercial layer-lines, ISA Brown, New Hampshire, Skalborg and a cross of New Hampshire(NH) and Skalborg (Sk), were infected with A. galli eggs. The birds were examined for the presence of parasite eggs and parasites at weeks 3, 6 and 9 post infection (pi).

3. At week 6 pi the chickens of the NH line harboured more larvae compared with the three other lines. The Sk line chickens excreted more A. galli eggs throughout the study compared with the other lines. Female worms in the Sk line were more fecund than the worms in the other lines. Male and female worms recovered from the Sk line at week 9 pi were longer. Male worms recovered from the NH line 6 weeks pi were shorter than male worms from the other lines. Female worms recovered from the NH line were shorter than the female worms from the ISA line and the Sk line. No differences were seen in weight gain among the 4 lines.

4. The results suggest that genetic factors are involved in the establishment and survival of A. galli in the intestine of layers. Further studies are needed to elucidate the genetic mechanisms behind the observed parasitological findings.
\end{abstract}

\section{INTRODUCTION}

The behaviour of laying hens has been studied intensively during the last decades and it has been shown that normal behavioural traits such as perching, nesting and dust bathing cannot be performed in conventional cage systems (Abrahamsson and Tauson, 1995). In Denmark, this has contributed to an increased public demand for meat and eggs produced in systems where the animals have free access to outdoor areas. In free-range production systems the birds are kept in deep-litter systems with free access to outdoor runs, and fed either organic or conventional feed. However, the risk of helminth infections is higher in such systems with production losses due to increased feed consumption and reduced animal welfare. Among the most commonly observed helminths in organic and free-range systems in Denmark is the ubiquitous nematode Ascaridia galli (Permin and Hansen, 1998; Permin et al., 1999). Anthelmintics have been used extensively over many years to control this helminth. However, due to drug residue concerns, alternative approaches are needed for control in free-range poultry production systems.
This could include the use of lines of chickens naturally resistant to helminth infections. Individual variation in natural resistance to disease is a widespread phenomenon attributed to genetic control of the immune system, and it may therefore be possible to identify specific differences in susceptibility to many diseases, including those of chickens (Bumstead et al., 1991). However, very little is known about genetic susceptibility to parasitic infections, particularly helminth infections in chickens, even though such knowledge could have a practical application in selecting, or breeding suitable layer-lines for organic and free-range systems.

The objective of our study was to compare the establishment and effect of $A$. galli infections in 4 different layer-lines, thereby exploring the possible influence of the genetic background of chickens on helminth infections.

\section{MATERIALS AND METHODS}

\section{Experimental animals}

Four different commercial layer-lines, ISA Brown, New Hampshire (NH), Skalborg (Sk)

Correspondence to: A. Permin, Department of Veterinary Microbiology, The Royal Veterinary and Agricultural University, Dyrlægevej 2, 1870 Frederiksberg C, Denmark. E-mail: ape@kvl.dk

Accepted for publication 3rd September 2002. 
and a cross of New Hampshire and Skalborg $(\mathrm{NH} \times \mathrm{Sk})$ were used for the experiment. Prior to the experiment, the hens had been reared in a parasite-free environment. Forty hens were allocated to each group, a total of 160 animals. The chickens, which were 60 weeks of age at the beginning of the experiment, were placed in a straw-bedded pen allowing $0.2 \mathrm{~m}^{2}$ of space per animal. All animals had free access to water and feed, and the pen was cleaned once a week to avoid uncontrolled re-infections with $A$. galli.

\section{Parasite material}

Adult A. galli worms were collected from naturally infected hens in a layer flock $20 \mathrm{~km}$ from Copenhagen, Denmark. The female worms were isolated from the gastrointestinal tract, dissected and the eggs embryonated in $0 \cdot 1 \mathrm{~N}$ sulphuric acid as described by Permin et al. (1997). After $30 \mathrm{~d}$ of embryonation the infectivity of the eggs was assessed visually by looking for moving larvae in the eggs and the number of infective eggs per $\mu l$ of fluid was calculated. All birds were inoculated orally with a single dose of 500 infective eggs using a plastic Pasteur pipette.

\section{Sampling and analysis}

All the chickens were weighed weekly. From week 5 post infection (pi), faecal samples were collected from all infected animals at weekly intervals. Nematode eggs in faeces were quantified using a modified McMaster method with a lower detection limit of 20 eggs per g (EPG) as described by Permin and Hansen (1998). Ten birds from each group were slaughtered in weeks 3 and 6 pi, while the remaining 20 birds per group were slaughtered in week 9 pi. At necropsy the gastrointestinal tract, including the gizzard and the cloaca, was removed. Each intestine was opened longitudinally and the contents washed in a $100 \mu \mathrm{m}$ sieve. The collected material was preserved in $70 \%$ ethanol and later examined under a stereo microscope for the presence of adult and immature stages of $A$. galli. The worms were counted and the sex of the adults recorded. From each infected chicken 10 immature and 10 adult worms were isolated at random and their body lengths measured. The immature worms were measured using a digital image analysis system (Microvision ${ }^{\circledR}$, DTI, Lyngby, Denmark) and the adult worms measured by a ruler.

\section{Statistical analysis}

Group means of worm burdens and worm lengths were compared by one-factor analysis of variance (ANOVA) at each sampling date. Group means of the estimated faecal EPG of A. galli throughout the experiment, as well as of the recorded weight gains, were compared by repeated measures analysis. All analyses and calculations were performed using the data processing software GraphPad Prism $^{\circledR}$ with $P<0.05$ being considered significant.

\section{RESULTS}

\section{Clinical examination}

Overall, few birds died (Table 1) though the ISA group had a higher mortality than other groups. This was due to cannibalism. Otherwise no clinical signs were observed in the groups.

\section{Worm counts}

Table 1 presents the number of $A$. galli found in the 4 layer-lines 3, 6 and 9 weeks pi. No statistically significant differences were observed in the totals (larvae + adults) between the groups at any time point. Similarly, no differences were found in the number of larvae recovered at weeks 3 and 9 pi. However, at week 6 pi, the chickens of the NH line harboured significantly more larvae compared with the other three groups. The Sk line harboured more adult worms than the other lines at weeks 6 and $9 \mathrm{pi}$, although this trend was not statistically significant $(P=0 \cdot 10)$.

Table 1. Mean number ( $\pm S D$ ) of larvae, adult males and females, as well as total (adults + larvae) number of worms, recovered in 4 lines, ISA Brown (ISA), New Hampshire $(N H)$, New Hampshire $\times$ Skalborg $(N h \times S k)$ and Skalborg (Sk) 3, 6 and 9 weeks after inoculation with 500 Ascaridia galli eggs. Total mortality is given in the last column

\begin{tabular}{|c|c|c|c|c|c|c|c|c|c|c|c|c|c|c|c|c|}
\hline & \multicolumn{5}{|c|}{ Week 3} & \multicolumn{5}{|c|}{ Week 6} & \multicolumn{5}{|c|}{ Week 9} & \multirow[t]{2}{*}{ Total mortality } \\
\hline & Larvae & $\mathrm{M}$ & $\mathrm{F}$ & Total & $N$ & Larvae & M & $\mathrm{F}$ & Total & $N$ & Larvae & M & $\mathrm{F}$ & Total & $N$ & \\
\hline ISA & $\begin{array}{c}25 \cdot 2 \\
(19 \cdot 1)\end{array}$ & $\begin{array}{c}0 \\
(0)\end{array}$ & $\begin{array}{c}0 \\
(0)\end{array}$ & $\begin{array}{c}25 \cdot 2 \\
(19 \cdot 1)\end{array}$ & 10 & $\begin{array}{c}1 \cdot 1 \\
(2 \cdot 1)\end{array}$ & $\begin{array}{c}1.4 \\
(1.9)\end{array}$ & $\begin{array}{c}2 \cdot 5 \\
(2 \cdot 8)\end{array}$ & $\begin{array}{c}5 \cdot 1 \\
(4 \cdot 2)\end{array}$ & 8 & $\begin{array}{c}0.9 \\
(2.5)\end{array}$ & $\begin{array}{c}4 \cdot 4 \\
(3 \cdot 6)\end{array}$ & $\begin{array}{c}6 \cdot 1 \\
(3 \cdot 6)\end{array}$ & $\begin{array}{l}11 \cdot 3 \\
(6 \cdot 3)\end{array}$ & 17 & 5 \\
\hline $\mathrm{NH}$ & $\begin{array}{c}33 \cdot 2 \\
(23 \cdot 5)\end{array}$ & $\begin{array}{c}0 \\
(0)\end{array}$ & $\begin{array}{c}0 \\
(0)\end{array}$ & $\begin{array}{c}33 \cdot 2 \\
(23 \cdot 5)\end{array}$ & 10 & $\begin{array}{c}14 \cdot 6 \\
(19 \cdot 6)\end{array}$ & $\begin{array}{c}1 \\
(2.5)\end{array}$ & $\begin{array}{c}1.3 \\
(3 \cdot 2)\end{array}$ & $\begin{array}{c}16 \cdot 9 \\
(18 \cdot 5)\end{array}$ & 10 & $\begin{array}{c}1.9 \\
(5.5)\end{array}$ & $\begin{array}{c}3 \cdot 2 \\
(4 \cdot 1)\end{array}$ & $\begin{array}{c}3.5 \\
(4.8)\end{array}$ & $\begin{array}{c}8.8 \\
(8.3)\end{array}$ & 20 & 0 \\
\hline $\mathrm{NH} \times \mathrm{Sk}$ & $\begin{array}{c}27 \cdot 8 \\
(22.6)\end{array}$ & $\begin{array}{c}0 \\
(0)\end{array}$ & $\begin{array}{c}0 \\
(0)\end{array}$ & $\begin{array}{c}27 \cdot 8 \\
(22 \cdot 6)\end{array}$ & 10 & $\begin{array}{c}1.2 \\
(1.3)\end{array}$ & $\begin{array}{c}2.7 \\
(4.6)\end{array}$ & $\begin{array}{c}3 \cdot 3 \\
(5 \cdot 5)\end{array}$ & $\begin{array}{c}7.2 \\
(9.5)\end{array}$ & 9 & $\begin{array}{c}0.2 \\
(0 \cdot 5)\end{array}$ & $\begin{array}{c}4.2 \\
(5.4)\end{array}$ & $\begin{array}{c}3.6 \\
(5 \cdot 0)\end{array}$ & $\begin{array}{c}8 \cdot 1 \\
(10 \cdot 0)\end{array}$ & 19 & 2 \\
\hline $\mathrm{Sk}$ & $\begin{array}{c}24 \cdot 8 \\
(30 \cdot 1)\end{array}$ & $\begin{array}{c}0 \\
(0)\end{array}$ & $\begin{array}{c}0 \\
(0)\end{array}$ & $\begin{array}{c}24 \cdot 8 \\
(30 \cdot 1)\end{array}$ & 10 & $\begin{array}{c}0 \cdot 1 \\
(0 \cdot 3)\end{array}$ & $\begin{array}{c}6.8 \\
(9.0)\end{array}$ & $\begin{array}{c}5 \cdot 4 \\
(7 \cdot 6)\end{array}$ & $\begin{array}{c}12 \cdot 3 \\
(16 \cdot 2)\end{array}$ & 9 & $\begin{array}{c}0 \cdot 1 \\
(0 \cdot 2)\end{array}$ & $\begin{array}{c}7 \cdot 1 \\
(8 \cdot 1)\end{array}$ & $\begin{array}{c}6.9 \\
(8.7)\end{array}$ & $\begin{array}{c}14.2 \\
(16 \cdot 7)\end{array}$ & 19 & 2 \\
\hline
\end{tabular}




\section{Parasite egg excretion}

The estimated mean faecal excretion of A. galli eggs in the 4 lines is given in the Figure. All lines excreted eggs 5 weeks pi. The chickens of the Sk line excreted significantly more A. galli eggs throughout the study compared with the other lines. The $\mathrm{NH}$ and the $\mathrm{NH} \times \mathrm{Sk}$ lines excreted relatively few eggs throughout the study, whereas the ISA line had a slightly higher EPG. However, no significant differences were found between any of these three lines.

\section{Fecundity}

The mean fecundity of the worms in each line was estimated for each hen as the EPG per female worm at the time of the post-mortem examination. However, due to a technical error, faecal samples were not taken from animals slaughtered at week $6 \mathrm{pi}$. The mean fecundity values for the worms recovered 9 weeks pi were $137 \pm 160 \mathrm{EPG} /$ Female (ISA), $132 \pm$ $115 \mathrm{EPG} /$ Female (NH), $65 \pm 82 \mathrm{EPG} /$ Female $(\mathrm{NH} \times \mathrm{Sk})$, and $301 \pm 224 \mathrm{EPG} /$ Female $(\mathrm{Sk}) . \mathrm{A}$ one-way analysis of variance demonstrated that the worms in the Sk line were significantly more fecund than the worms in the other lines. No difference in worm fecundity was found between any of the other three lines.

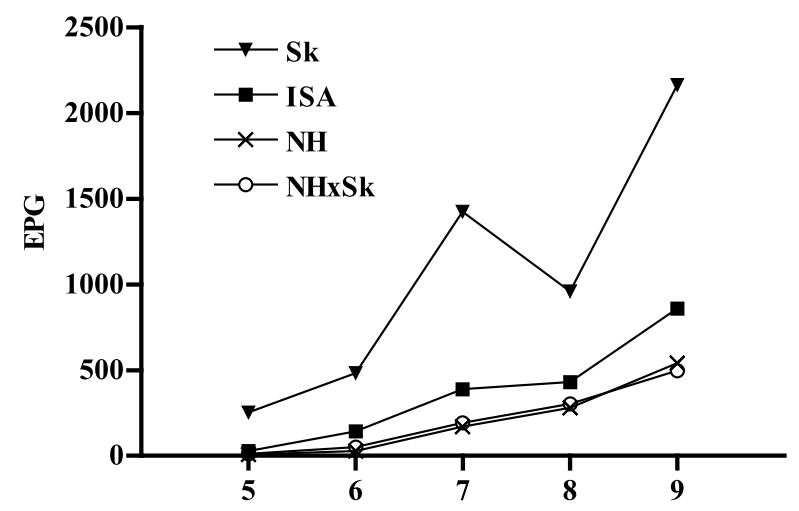

Figure 1. Estimated mean faecal excretion of Ascaridia galli eggs from week 5 to week 9 post infection in 4 layer-lines, ISA Brown (ISA), New Hampshire (NH), New Hampshire $\times$ Skalborg $(\mathrm{NH} \times \mathrm{Sk})$ and Skalborg $(\mathrm{Sk})$.

\section{Worm lengths}

Male and female worms recovered from the $\mathrm{Sk}$ line at week 9 pi were significantly longer than the worms from the other lines (Table 2). When comparing the lengths of the worms recovered 6 weeks pi, it was found that the female worms from the $\mathrm{Sk}$ line were longer than the female worms from the $\mathrm{NH}$ line, as well as the $\mathrm{NH} \times \mathrm{Sk}$ line. Similarly, the male worms from the Sk line were longer than the male worms from the $\mathrm{NH}$ line. Furthermore, the male worms from the NH line 6 weeks pi were shorter than the male worms from the other lines and the female worms from the NH line were shorter than the female worms from the ISA, as well as the Sk line. No significant differences in lengths of the larvae recovered at week 3 pi were found between any of the layer-lines, and too few larvae were recovered at weeks 6 and 9 pi for reliable comparisons.

\section{Weight gain}

The mean weight gains of the chickens of each line were very uniform and no significant differences were demonstrated.

\section{DISCUSSION}

It was found that there was no difference between any of the lines in total number of worms (adults + larvae) but on the basis of the significant difference in faecal egg counts, the Sk line appeared to be more susceptible to $A$. galli infections than the three other lines. The chickens of the Sk line also tended to harbour more adult worms than the other lines and these worms were significantly more fecund than the worms in the other lines. The differences in faecal egg counts were probably due to differences in fecundity of the worms rather than the actual number of worms harboured by the hens.

The findings that the male as well as the female worms recovered from the Sk line by weeks 6 and 9 pi were longer than the worms from the other lines clearly support the indication that the $\mathrm{Sk}$ line was more susceptible to A. galli infections.

Table 2. Mean lengths ( \pm S.D.) of larvae in millimetres, adult males and females recovered from 4 lines, ISA Brown (ISA), New Hampshire $(\mathrm{NH})$, New Hampshire $\times$ Skalborg $(\mathrm{Nh} \times \mathrm{Sk})$ and Skalborg $(\mathrm{Sk})$ 3, 6 and 9 weeks after inoculation with 500 Ascaridia galli eggs

\begin{tabular}{|c|c|c|c|c|c|c|c|c|c|}
\hline & \multicolumn{3}{|c|}{ Week 3} & \multicolumn{3}{|c|}{ Week 6} & \multicolumn{3}{|c|}{ Week 9} \\
\hline & Larvae & Males & Females & Larvae & Males & Females & Larvae & Males & Females \\
\hline ISA & $3 \cdot 1(0 \cdot 9)$ & - & - & $1.9(0 \cdot 6)$ & $40 \cdot 5(10 \cdot 4)$ & $52 \cdot 9(12 \cdot 9)$ & $3 \cdot 2(1 \cdot 1)$ & $52 \cdot 0(10 \cdot 5)$ & $70 \cdot 8(19 \cdot 0)$ \\
\hline $\mathrm{NH}$ & $3 \cdot 3(0 \cdot 7)$ & - & - & $2 \cdot 6(0 \cdot 7)$ & $30 \cdot 1(7 \cdot 3)$ & $40 \cdot 1(14 \cdot 6)$ & $2 \cdot 9(1 \cdot 1)$ & $50 \cdot 8(10 \cdot 1)$ & $65 \cdot 2(16 \cdot 3)$ \\
\hline $\mathrm{NH} \times \mathrm{Sk}$ & $3 \cdot 3(0 \cdot 8)$ & - & - & $3.5(1 \cdot 8)$ & $42 \cdot 0(9 \cdot 5)$ & $47 \cdot 5(7 \cdot 9)$ & - & $49 \cdot 7(11 \cdot 0)$ & $72 \cdot 4(17 \cdot 8)$ \\
\hline $\mathrm{Sk}$ & $3 \cdot 1(0 \cdot 7)$ & - & - & - & $47 \cdot 8(8 \cdot 4)$ & $60 \cdot 5(16 \cdot 8)$ & - & $59 \cdot 2(9 \cdot 7)$ & $83 \cdot 3(14 \cdot 9)$ \\
\hline
\end{tabular}


Another interesting finding was that the male worms recovered from the $\mathrm{NH}$ line at week $6 \mathrm{pi}$ were shorter than the males from the other lines. Similarly, the female worms recovered from the $\mathrm{NH}$ line were shorter than the females from two of the other lines (ISA and Sk). This, together with the finding that the chickens of the NH line harboured more larvae at week 6 pi than the other lines, suggests that $A$. galli might have developed more slowly in the $\mathrm{NH}$ line which could be interpreted as a further indication of resistance to the parasite.

No differences in weight gains or gross pathology were found between the 4 lines, suggesting that the difference in susceptibility probably would be more important to the epidemiology of the infection rather than to the welfare of any particular infected animal.

Although no correlation could be established in the present study, the results suggest there may be a genetic element involved in A. galli infections in chickens. This was observed in another study comparing the establishment of $A$. galli in Danish Landrace and Lohman Brown chickens (Permin and Ranvig, 2001). The Major Histocompatibility Complex (MHC) is a cluster of genes which encodes cell-surface glycoproteins that are involved in antigen recognition in immune responses. The MHC, or the B-complex as it is called in chickens, is closely associated with individual differences in susceptibility to many poultry diseases, such as Marek's disease (Briles et al., 1982), Rous sarcoma virus (Plachy et al., 1992), fowl cholera caused by Pasteurella multocida (Lamont et al., 1987), coccidiosis (Bumstead and Millard, 1987; Caron et al., 1997) and salmonellosis (Cotter et al., 1998). Although information on the involvement of the B-complex in resistance to helminth infections is very limited, Wetherall and Groth (1992) have shown that in mice certain MHC haplotypes are associated with resistance to helminths. Whether or not the B-complex is involved in the apparent difference in susceptibility to $A$. galli infections of the 4 lines examined in the present study remains to be investigated.

In summary, the results suggest that genetic background might influence $A$. galli infections in chickens. Thus, the Sk line is presumably more susceptible, whereas the NH line appeared to be less susceptible to the parasite. Furthermore, the apparent susceptibility of the Sk line to A. galli was reversed by crossing with the $\mathrm{NH}$ line. Therefore, it seems likely that it will be possible to identify chicken lines that are less susceptible to parasite infections and thus more suitable for free-range systems. It would be worthwhile establishing whether the genetic component behind the observed differences between the layer-lines is associated with different haplotypes of the B-complex.

\section{ACKNOWLEDGEMENTS}

We would like to acknowledge Per Isaksen for handling all the animals and taking the samples. Furthermore, we thank Rikke Frahm Lundvig and Margrethe Pearman for counting the parasite eggs and worms. Financial support was given by the Ministry of Agriculture (the FØJO I programme) and the Danish Council for Development Research (Danida).

\section{REFERENCES}

Abrahamsson, P. \& Tauson, R. (1995) Aviary systems and conventional cages for laying hens. Effects on production, egg quality, health and bird location in three hybrids. Acta Agriculturæ Scandinavica, 45: 191-203.

Briles, W.E., Briles, R.W., Pollock, D.L. \& Pattison, M. (1982) Marek's disease resistance of B (MHC) heterozygotes in a cross of pure-bred Leghorn lines. Poultry Science, 61: 205-211.

Bumstead, N. \& Millard, B.M. (1987) Genetics of resistance to coccidiosis: response of inbred lines to infection by Eimeria tenella and Eimeria maxima. British Poultry Science, 28: $705-715$.

Bumstead, N., Millard, B.M., Barrow, P.A. \& Cook, J.K.A. (1991) Genetic basis of disease resistance in chickens. in: Owen, J.B. \& AxFord, R.F.E. (Eds) Breeding for Disease Resistance in Farm Animals, pp. 10-23 (Wallingford, Commonwealth Agricultural Bureau).

Caron, L.A., Abplanalp, H. \& Taylor, R.L.J. (1997) Resistance, susceptibility and immunity to Eimeria tenella in Major Histocompatibility (B) Complex congenic lines. Poultry Science, 76: 677-682.

Cotter, P.F., Taylor, R.L. \& Abplanalp, H. (1998) B-complex associated immunity to Salmonella enteritidis challenge in congenic chickens. Poultry Science, 77: 1846-1851.

Lamont, S.J., Bolin, C. \& Cheville, N. (1987) Genetic resistance to fowl cholera is linked to the Major Histocompatibility Complex. Immunogenetics, 25: 284-289.

Permin, A., Bisgaard, M., Frandsen, F., Pearman, M., Kold, J. \& Nansen, P. (1999) The prevalence of gastrointestinal helminths in different poultry production systems. British Poultry Science, 40: 439-443.

Permin, A. \& Hansen, J.W. (1998) The Epidemiology, Diagnosis and Control of Helminths in Poultry. (Rome, FAO).

Permin, A., Pearman, M., Nansen, P., Bisgaard, M. \& Frandsen, F. (1997) An investigation on different media for embryonation of Ascaridia galli eggs. Helminthologia, 34(2): 75-79.

Permin, A. \& Ranvig, H. (2001) Genetic resistance in relation to Ascaridia galli in chickens. Veterinary Parasitology, 102(1,2): 101-111.

Plachy, J., Pink, J.R.L. \& Hala, K. (1992) Biology of the chicken MHC (B-Complex). Critical Reviews in Immunology, 12: 47-79.

Wetherall, J.D. \& Groth, D.M. (1992) The Major Histocompatibility Complex and parasite immunity. in: Yong, W.K. (Ed) Animal Parasite Control Utilizing Biotechnology, pp. 353-386 (London, CRC Press England). 